\title{
Salsa Dance and the Transformation of Style: An Ethnographic Study of Movement and Meaning in a Cross-Cultural Context
}

\author{
Joanna Bosse
}

\section{Introduction}

0 ver the last century perennial surges in the popularity of Latin American couple. dance genres such as tango and rumba in the United States have served as lightning rods for debate on issues of morality, performance, and identity. These "crazes" have fueled the collective American imagination, reinforcing a type of Latin American exotica that prevailed throughout the twentieth century and into the next. Consequently, they have also fostered an entirely new style of performance as white Americans borrowed-or perhaps better stated, appropriated-these genres for their own. For instance, the two styles of tango performed by ballroom dancers today, some one hundred years after its introduction to American audiences in theaters and exhibition performances, is sufficiently distant from its Argentine roots to be considered an entirely different dance employing different movements, rhythms, and musical accompaniment.

This article explores this particular brand of cross-cultural borrowing through an ethnographic accounting of a salsa dance formation team in central Illinois. Salsa is the latest of the Latin dance crazes, and since the early r 990 s the genre has experienced increased attention from mainstream American audiences who have invested significant resources in order to learn to dance salsa. Formation teams are presentational performance ensembles, in this case combining salsa; ballroom; and staged, theatrical dance, and generally draw their enthusiasts from ballroom dance circles. This article documents the creation of a salsa formation team and the manner in which salsa and ballroom were merged in its

Joanna Bosse is currently assistant professor of ethnomusicology at Bowdoin College. Her work involves the ethnographic study of social dancing in the United States and the relationship between music and movement in social dance contexts. She has presented papers to the Society for Ethnomusicology, the Society for American Music, the Society of Dance History Scholars, and various conferences on music and dance. Her research was awarded the Nahumck Award for Dance Research by the Society for Ethnomusicology in 200r. She is currently working on a monograph entitled Becoming Beautiful: Ballroom Dance and the Transformative Experience, an ethnographic study of amateur ballroom dance. 
service; it suggests that the adoption of this new style of performance was a precarious and creative attempt at refashioning identity for its members.

Being outsiders to the local salsa dance community and newcomers to salsa, the team's members hoped their participation would improve both their dancing and their social standing among local Latin American salsa dancers. They were not alone. During my fieldwork in Midwestern salsa dance clubs, many non-Latinos, most of whom were white Americans but also individuals from East and South Asia, the Middle East, Eurasia, and Europe, employed a number of strategies to learn a style of salsa dance that they not only found enjoyable and comfortable to perform but that would be socially recognized as legitimate by the small and close-knit salsa dance community. The Dancing Illini Salsa Formation Team (hereafter referred to as SFT) was a bold, and perhaps misguided, endeavor to bring together a diverse group of individuals, with competing goals and conflicting notions of what salsa dancing was, for the goal of presentational performance in a ballroom milieu.

This article is part of a larger ethnographic project documenting social couple dance in central Illinois and the intersection of various dance communities as they came together on dance floors throughout the region (see Bosse 2004). My work centered on the Regent Ballroom and Banquet Center in Savoy, Illinois, a ballroom studio and performance space that also plays host to a variety of other kinds of events such as late-night salsa events and milongas. As a dance ethnographer and ethnomusicologist, participant-observation formed the core of my method. I lived and danced with my informants from I 996 to 2002 and then returned to the region in 2005 for follow-up work. In addition to conducting formal and informal interviews; documenting classes, rehearsals, and dance events at the Regent and in the wider area with video and audio recordings; working at the Regent in a variety of roles, from bartender to dance instructor; and attending well over two hundred social dances, I learned every couple dance genre performed in the region, including all the ballroom dances, the hustle, swing, salsa, Argentine tango, and country two-step. The SFT emerged very early in my fieldwork and dissipated quickly, lasting for less than one year. Even so, it serves as a fertile case study for examining cross-cultural borrowing and the ways in which new dance styles are generated.

\section{The Salsa Formation Team}

A phenomenon primarily belonging to the world of ballroom dance, formation teams result from a blending of theatrical stage dancing and couple dance. They are comprised of two to sixteen couples performing a choreographed routine that emphasizes virtuosic levels of synchrony, stylized gesture, and partner swapping in a presentational context. In contemporary performances the teams present a medley of ballroom genres in one extended performance. They are common among college-age dancers and are often sponsored by college and university student activity organizations. The SFT, formed in 1996 by two University of Illinois graduate students, was a departure from this standard in one important way: it was a group newly formed with the express purpose of performing only salsa dance.

Having emerged during a time of increased cross-cultural contact on the dance floors 
of Urbana-Champaign, Illinois, a small Midwestern college town, the team presented three public performances of their choreographed routine in costume-with black dress and domino masks adorned with beads and feathers-before disbanding later that same year. Though a relatively isolated instance, the formation team serves as a representative case of the strategies and methods employed by outsiders interested in performing Latin American couple dances, and in some ways it is iconic of the popularization of Latin dances among mainstream American audiences throughout the twentieth century. The team's founding can be understood as an expression of ambivalence among the group's members as they collectively wrestled with notions of ethnicity, race, and class while at the same time inhabiting different subject positions in relationship to these concepts. By highlighting some aspects of the process through which salsa was transformed by a ballroom dance aesthetic through the formation team-an approach that I hope will shed light on stylistic transformation in cross-cultural borrowing more generally-I aim to illuminate how prevailing conceptions of ethnicity, class, and physicality are encoded in style and embedded in aesthetic disposition.

The decision to form such a team exclusively for the performance of salsa was controversial. Local salsa dancers felt that the qualities inherent in ballroom dance and formation team performance were contrary to the aesthetic of salsa dancing, and college-age ballroom dancers felt somewhat betrayed that the team focused on the one dance with which they had the least experience and the least social credibility to perform. Furthermore, the two leaders, Gabrielle and Lisa, both non-Latinos hailing from the metropolitan areas of Chicago and Miami, respectively, were not recognized as accomplished salsa or ballroom dancers; as such they were open to criticism from several sides. ${ }^{1}$ Though not Latinas, the two women learned salsa dancing during their adolescence in their hometowns from their Latin American childhood friends. They felt a degree of ownership for salsa that was not legitimated by the local salsa dance community, who were unaware of the women's earlier experiences.

Although the team was comprised of a heterogeneous group of individuals, including members from Europe, the Middle East, Asia, and four from Latin America, the majority identified as white Americans or Americans of mixed or ambiguous ethnic affiliation. Most members were affiliated in some way with the University of Illinois: undergraduates, graduate students, employees, or research fellows. Collectively they brought to the team a diverse set of experiences, and there was little consistency in terms of their selfidentification vis-à-vis family history, ethnicity, or their relationship to dance (salsa or any other type). Despite this diversity, however, members of the group were of a similar class status and shared a particular cosmopolitan aesthetic disposition that obscured the otherwise international and heterogeneous constitution of the group. ${ }^{2}$

In addition to their shared cosmopolitanism, members of the SFT were bound by two important common elements. First, the members felt in some way be marginal to, if not completely outside of, the local salsa dance community and perhaps Latin American culture generally, and they were in some way insecure about their salsa dance abilities. Even the few Latin Americans who joined the group expressed feelings of marginality within the salsa dance community, and they hoped that their participation in the team would remedy 
this situation. Two of the dancers hailed from Central America, and they felt their style of salsa performance was valued significantly less than Caribbean and New York styles. Ricardo, one such dancer, stated that he hoped that working with professional dance coach David Lin would "add some class" to his dance style, making it more sophisticated and widely respected. Two other members were light-skinned, blue-eyed Brazilians who were not able to dance salsa at all, did not speak Spanish, and were often not recognized as Latin American by other Latinos. They joined the group in order to better connect to the local pan-Latin American community. Like their non-Latin counterparts in the SFT, these Latin American dancers participated in the group in an attempt to work through feelings of marginalization and to renegotiate their social position within the tight-knit salsa dance community.

A second commonality shared by the group's membership was that they were in some way dissatisfied with their style of salsa dancing and hoped their participation in the SFT would improve it. All were familiar enough with salsa to know at least the basic footwork pattern, and some members were quite advanced. All had attended a number of social salsa dance events in the region.

Finally, although the SFT was comprised of a diverse collection of individuals, they all hoped that through the SFT they would learn a new set of physical habits with regard to salsa performance and their own sense of self. In his book Playing Indian, Philip Deloria states that theater and disguise "readily calls the notion of fixed identity into question. At the same time, however, wearing a mask also makes one self-conscious of a real ' $m e$ ' underneath. The simultaneous experience is both precarious and creative, and it can play a critical role in the way people construct new identities" ( 1998,7$)$. Participation in the SFT was itself a "precarious and creative" attempt at refashioning identity for its members, who eventually became frustrated with their inability to step outside of their own cultural predispositions about movement, dance, and their own bodies.

Drawing an analogy between movement within a given cultural group and dialects of a spoken language, I employ the term movement dialect throughout this article as a means for conceptualizing dance styles as simultaneous expressions of individuality and markers of cultural affinity and difference. Dance involves a set of movements with shared, culturally agreed upon meanings. The way my informants moved within space was a powerful, culturally conscripted bundle of signs through which they expressed their place in the world. My larger research has involved understanding how a great variety of dance styles that articulate identity at both the individual and collective levels have come to be considered the performance of a single genre.

While drawing upon the similarities between spoken language and dance has its limitation, doing so in this instance has proven helpful. For just as speech, and sensibilities about it, shape the way we make culturally salient linguistic sounds, so, too, our movement dialect - the way we have internalized our understanding of our bodies and the kinds of movement that are possible and appropriate- patterns the way we understand movement. Using the analogy of a dialect is helpful for understanding how aspects of an individual's "style" are culturally grounded, just as spoken dialects are attributed to social groupings rather than individual caprice. Dance is often a medium that encourages a greater degree 
of individuality than speech patterns, but it is nonetheless developed within a certain set of culturally agreed upon limitations, resulting in an individual style that still communicates cultural affinities. One's habitus is encoded in movement and informed by the specific juxtaposition of predispositions related to class, race, gender, ethnicity, geographic region, generation, and any number of other influential factors. Therefore, while every person's dance style is to some degree unique, it also contains aspects of a common lexicon, of a shared habitus (Bourdieu I977). Movement dialect is, then, one aspect of habitus that speaks to the structural nature of movement and embodiment, its manifestation in practice, and its relationship to past experience, individual and shared values, and the objective conditions of one's life. However, the analogy suggested between movement and language should not be taken too literally. I am not suggesting that movement dialect or the more colloquial concept of "body language" has a syntax derived from linguistic grammatical conventions, nor that spoken language is a more fundamental or innate semiotic system to which other communicative systems should necessarily be compared.

Generally, it is extremely difficult, if not impossible, to completely assume the movement dialect of another cultural group. Thus, the cross-cultural performance of a dance genre is filtered through a variety of movement dialects to create something stylistically different and new. Within a different analytical framework, these styles might be understood as participatory discrepancies (Keil r987; 1995). I would suggest that in this particular context, however, the stylistic discrepancies were interpreted as signifiers of cultural difference and were employed instrumentally to articulate social affinity.

The translocal nature of salsa has given rise to a wealth of stylistic variation (Aparicio I 998; Duany I 984; Hosokawa I 997; Loza I 993; Manuel I 994; Waxer 2002a, 2002b). In central Illinois the level of specificity was largely bound to nation-state affiliations. My informants talked of a Cuban style of salsa; Colombian, Dominican, and Mexican styles; and, more specifically, New York, Miami, or Chicago styles. Furthermore, within my field site, a new collection of styles eventually emerged among the largely non-Latin American newcomers to the genre. Though outsiders learned the basic rhythm of footwork patterns and a variety of moves, they had difficulty performing other, more subtle aspects of the dance, so much so that their approximations were recognized as stylistically distinct-alike enough to be called salsa dance but an altogether different kind of salsa dance. Never in my work with experienced salsa dancers did they frame the styles of white salsa dancers as "beginners," or their different styles of salsa dance as elementary, regardless of the individual's level of ability. No one ever suggested that these approximations of salsa dancing were an earlier stage of what would eventually develop into an appropriate style, or that they could eventually learn to dance like a Cuban, for example. Rather, it was generally understood that the lack of Latin American heritage was an essential barrier to gaining complete fluency in the dance, and the highest level of acceptance one could hope for at my field site would be something like, "You dance very well for a white guy."

The differences between all of these styles of salsa are in part a result of the different movement dialects that inform them. My informants were acutely aware of the variety of salsa dance styles represented on the floor-divisions that undercut any kind of simplistic Latin/non-Latin dichotomy-and much of my fieldwork was spent sorting out 
how different individuals prioritized these different styles in terms of prestige, class, and authenticity. This was especially true for members of the SFT, who were seeking to transform their own style of performance in the hopes of gaining acceptance and legitimacy within the local salsa dance scene. Ultimately, this approach failed to garner its members the prestige for which they hoped. One cause for the frustration is the paradoxical nature of movement dialects and identity more generally.

As Bourdieu (1977) states, habitus simultaneously structures performance as it is structured by it. This paradoxical nature of habitus is, in part, what leads to individual and collective stylistic variation and the inability to completely adopt the dance style of another. Through their participation in the SFT, members may have gained more experience dancing salsa, but they were no more able to fit in stylistically than they were before they joined the team. In fact, performance of the virtuosic ballroom-styled moves at social salsa dances served primarily as a signifier that these individuals were trained in the ballroom and, consequently, were not "genuine" or "authentic" salsa dancers. That they could not step outside of their movement dialect completely, however, did not preclude my informants from exploring its boundaries and shaping it with new experiences. In the attempt something new was born-a new sense of self and a changed, or new, style of performance.

The fusion of salsa dance and theatricalized, formation team performance led to a formal presentation that was significantly different from the improvisatory salsa dancing that occurred at any local nightclub venue. But participation in the ensemble also shaped the individual dance styles of its members and had lasting effects on their individual performance in clubs, bars, and other improvisatory social dance contexts. Within this context of cross-cultural borrowing and syncretic blending, two important factors contributed to the particular type of transformation that occurred. First, the use of a ballroom pedagogical framework established a different prioritization of gestures, relocating movements that are seldom named in conventional Latino/a dance contexts from their domain in tacit knowledge to an explicit, codified, and rationalized lexicon of moves (see also Bosse 2004 and Penny I 997). Second, the structuring capabilities of movement dialect resulted in a resignification and fetishization of movements that were not congruent with, or affirmed by, the members' movement dialects.

\section{Pedagogical Framework and the Fetishization of Hips}

All members stated they joined the SFT not because they were particularly interested in presentational performance but because it was a convenient opportunity to improve their social dancing and learn from "the best teacher in town."The team was a viable option for its members because it utilized a number of strategies that resonated with their own sensibilities. It provided an alternative pedagogical approach that had an implicit "common sense" value to this group of college students and graduates, who were accustomed to educational practices rooted in Western European pedagogical traditions. The method employed by David Lin, the team's professional coach, was based in decades of codified ballroom technique that introduced isolated components of the dance movement slowly, without music, in a hierarchical order. These components were broken down into 
the smallest cells and taught individually with an extensive use of mediating language; only then was the dance reconstructed by piecing the cells together. This approach was a significant departure from most other methods for learning salsa. Many Latin Americans stated that they were socialized to salsa from a young age and that they learned by watching family members dance and from being encouraged to dance in childhood (see Berrios-Miranda 2003). Subsequently, most of the local salsa dance classes taught by Latinos/as involved rote teaching-they demonstrated the move over and over again in tempo with music and encouraged their students to model their movement. Many non-Latino/a beginner students found this approach chaotic and were disoriented by the degree of liberty and lack of "real instruction." The individuals who rejected this type of class found David Lin's ballroom-style pedagogy more amenable.

David Lin was recruited for the position of coach for the SFT because of his reputation as an excellent teacher and enthusiastic supporter of salsa dance activities. As a ballroom dance professional, a newcomer to salsa, and owner of the dance floor that hosted the most popular weekly salsa dance event in the region, Lin was very interested in the variety of salsa dance styles he witnessed on the floor each week. Collaboration with the SFT provided Lin with an opportunity to engage these stylistic discrepancies and to identify, for the purposes of codifying a pedagogical method for salsa, a style that was teachable, distinctive, and as "authentic" as possible. As he stated in SFT rehearsals, he wanted to be able to teach his students to dance "as much like Latino salsa dancers as possible," although by Latino, he meant middle- and upper-class Cubans rather than Colombians or Mexicans, whose styles were considered less sophisticated within the local salsa dance community. Understanding that the goal of its members was to improve their salsa dance skills for social dance contexts, Lin stressed to members that the moves the SFT would perform were borrowed from "real salsa dancers" and could be modified for use in club dancing.

Although Lin was an extremely accomplished dancer, he nevertheless consulted with other professional ballroom instructors of Latin American descent. He worked most extensively with Enio Cordoba, a California-based professional ballroom competitor and coach who had positioned himself as a cultural translator of Latin American dance genres for U.S. audiences. Cordoba provided strategies for breaking down salsa dance into isolated components, for prioritizing these components, and for teaching them to newcomers.

One of the most difficult aspects of salsa dance to convey to newcomers is the distinctive counter-body motion-a product of a particular combination of knee, hip, and ribcage movements. Generally, the basic position requires one bent knee while the other remains straightened, and the basic movement involves alternating bent and straight knees. This juxtaposition of one bent knee and one straightened knee causes a secondary response as the hip above the straight knee juts out slightly. Simultaneously, the ribcage moves in the direction of the bent knee, opposite the direction of the extended hip. The position of the ribcage serves to balance the weight distribution of the extended hip. With each beat of the music, salsa dancers alternate bent and straight knees and direction of the ribcage, maintaining a level height (with little rise and fall or bobbing of the head) and a balanced center of gravity. Another secondary result of this motion (in addition 
to the hip movement) is that the arms move forward and back in small circles, following the direction of the ribcage and shoulders. This combination of movements is very subtle and can be executed in a number of ways, depending upon other elements such as arm movement, posture, foot placement, and direction of knee movement; however, it was present to varying degrees among most, if not all, of the Latin American salsa dancers with whom I worked. This is not to say that all Latin Americans were great salsa dancers, but generally speaking this particular issue was not a problem. During my six years of fieldwork I never personally witnessed a salsa dancer specifically reference this aspect - the counter-body motion-in any way. They generally focused on the rhythm and placement of the footwork. Though the Latin American salsa dancers I worked with understood that their hips were moving, their focal awareness was invested in the active engagement of the knees and virtuosic footwork. ${ }^{3}$

In contrast, outsiders to the genre overlooked the complex interplay of body movements and singled out only the movement of the hips as the root of salsa's energy and perceived sexual appeal. Many fixated on the hip movement and worked exclusively on its performance, forsaking the necessary footwork and knee and ribcage movements that actually make it possible. This movement was not a typical component of their movement dialect and as such, it was very difficult to master and became something upon which newcomers fixated. This fetishization of hip movement on the part of my informants who were new to salsa resulted, in part, from the fact that the requisite counter-body movement was not a typical component of their movement dialect.

Since the popularization of the rumba in the I 930 , ballroom dance teachers have invested a great deal of time learning and standardizing this counter-body motion-what they call "Latin hip action" and "Latin walks" (or sometimes "Cuban walks")_-and many advanced ballroom dancers have learned to perform it (see Figure I). The method involves isolating the movement of the feet, knees and thighs, hips, ribcage, shoulders, and arms; using extensive language to explain each aspect individually and subsequently their interconnectedness; and then repetition in front of a wall of mirrors, practicing first in place and then walking across the floor. Only then is the movement incorporated into a particular genre and aspects such as timing, rhythm of the music, and direction of movement introduced.

David Lin initially relied upon these ballroom methods for teaching counter-body motion and ribcage isolation to members of the SFT. The convention for ballroom performance, especially in presentational contexts, mandates a much more extreme display of counter-body movement as a means of marking one's skill and investment.

The subtle ribcage isolation in the performance of salsa dancers became much more extreme when learned through ballroom methods. Because of its difficulty, the ability to perform this move was highly valued among ballroom dancers not as a signifier of liberated sexuality but paradoxically as a sign of physical mastery and ultimate control. While some members of the SFT acquired this skill to varying degrees and approximations, others found it completely impossible. This one aspect of the dance consumed dancers' attention in the early rehearsals, and Lin grew increasingly frustrated. He turned to Cordoba for advice, who suggested that the motion not be introduced to beginner dancers precisely because they tend to fixate on this one aspect of the dance. He said, "That's 


\section{The Cuban Walk}

Start with your feet together. Without moving your body forward, take a short step forward with your left foot, bending your left knee.... and as you bend your left knee, be sure that your entire weight is on the heel of your right foot. Your right foot is flat on the floor, and your right knee should be straight.

Now try it with the other foot. Take a short step forward with your right foot. The right knee should be bent, and the weight should be on the heel of the left foot and the left knee straight. When you bend your knee be sure that you do not stoop. The body is held erect.
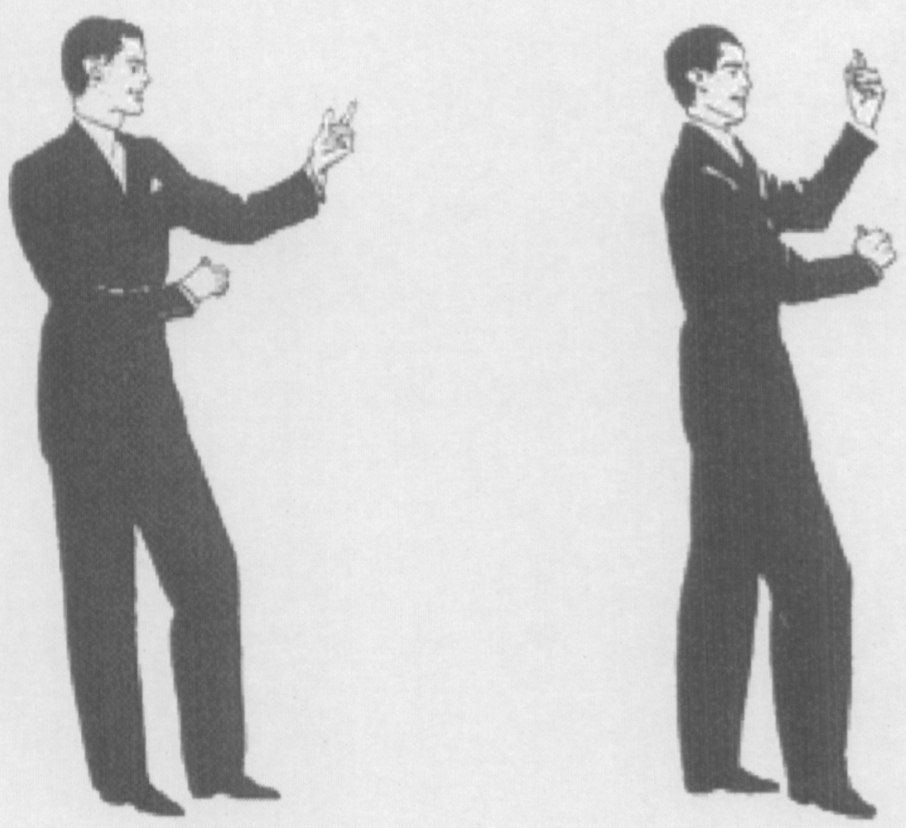

SIDE YIEW

112

Figure r. Description of the Cuban walk (now generally called "Latin walk") from the classic source of ballroom instruction, Arthur Murray $(1948,112)$. 
why I don't teach hip action [in the early courses] because then you get the hips and nothing [else]." Instead, he stated that he introduced ribcage and hip action later, to the more advanced dancers, and focused on knees and arms with beginners. He stated that he began by making sure his students dropped their elbows and learned what he called "double dutch"-an arm movement evocative of the popular jump rope game-in an attempt to learn the characteristic arm circles of salsa dancing. The general lack of fluency in ballroom technique among the dancers prevented many members of the team from quickly grasping counter-body motion and prohibited Lin from developing a particularly complicated or demanding routine. He focused more time than he had hoped teaching rudimentary steps and moves and was challenged to choreograph a routine that looked more difficult than it really was.

The notion of "correct" performance was extremely problematic. For Lin, "correct" implied adherence to ballroom standards, which, as has been suggested, were a significant departure from salsa dance conventions. Thus, even the most advanced salsa dancer would have difficulty performing "correctly" or "getting it right" within the context of the SFT. One of the goals for the SFT performance for Lin and the team's captains was a homogenization of performance so that all the members would eventually dance alike, in synchrony. This is a conventional trademark of formation teams. The personal goal of most of the team's members, however, was to improve their individual performance for social dance contexts, and they were much less interested in, or capable of, dancing exactly like their fellow team members. Furthermore, the diverse constituency of the group and the very nature of movement made the goal of dancing in total and perfect synchrony virtually impossible. Thus, it is important to remember throughout the discussion of this case study that Lin's frustration with the group's lack of virtuosity or ability to "get it" speaks to their inability to perform one unified style and is not necessarily indicative of the capabilities of the dancers to perform individually.

Lin eventually followed Cordoba's suggestion and abandoned attempts to teach counter-body motion to the team members, compelling them to work it out on their own. Although the SFT rehearsals were largely spent working out the intricate floor patterns, individuals also used the rehearsal time to work out this counter-body motion and other more subtle aspects of the dance, trying many different things and using the mirror to check the results, watching and learning from each other, performing each run-through with a different hip action or foot placement, and assessing which looked better or worse and felt most comfortable. Through Lin's endorsement, Irene, a member of the team and a newcomer to salsa with advanced training in ballroom and ballet, became representative of the "ideal" and the group's female members modeled their own performance on hers.

This strategy of breaking down the larger movement into smaller cells, such as arm movements separate from feet or hips, is central to the ballroom pedagogical approach. What this approach can fail to make clear is the relationship between intentional movements and the secondary movements that are the result of intentional movements. An easy example to consider is that of walking. When I choose to walk to the store, I explicitly understand this movement to involve leg movement and placing one foot in front of another. Even though this movement is, by adulthood, habitual, it is still cognitively, and 
perhaps physically, defined by leg movement. A secondary by-product of walking is a counter-body arm movement-swinging one's arms forward and back opposite to the leg movement. It is not considered integral to the act of walking, though, in fact, it usually is. Because it occurs as a reflexive balancing mechanism and is not taught explicitly, it is often something we identify as "natural." This is not to suggest that all such secondary movements are somehow innate or universal, although some are. Those with which I am concerned in the context of salsa dance were learned, but this learning occurred in tacit, and decidedly nonlinguistic, modes of acculturation that became habituated and internalized within dancers' movement dialects.

In the world of social dance, and especially the cross-cultural borrowing of Latin styles, this kind of prioritization of intentional and secondary movements can get lost in translation. In attempting to teach salsa dance to members of the SFT, David Lin isolated, named, and made explicit many components of salsa, including movements that were largely secondary and tacit within the movement dialects of most Latin performers of the genre. This resulted in a different style of movement than that typically performed by Latin American salsa dancers. The counter-body movement codified by ballroom dancers, as I have described above, is one such example.

Another important example for the SFT was arm movement. The arm circle characteristic of salsa dancing is much like the swinging of the arms that occurs in walking: it is a secondary balancing mechanism rather than a definitive or explicit move. No Latin American salsa dancer in my field site explicitly referenced the arm circles in teaching newcomers, with the exception of common suggestions to "relax the arms and let them move naturally." This direction proved to be too vague for many dancers, who were left not knowing what "relaxed" meant in the context of salsa dance. Using ballroom method and following Cordoba's suggestion of the "double dutch" exercise, Lin taught the SFT members how to trace small circles in the air with their hands, as if they were turning two imaginary jump ropes in the popular game "double dutch."This was initially introduced while the students were standing still and not contextualized rhythmically with the necessary footwork or tempo of the music. Because it was isolated, highlighted, and taught independently of the primary movements from which it is typically generated, the resulting style of arm motion performed by SFT members was radically different from that of salsa dancers. The arm circles were generally much larger than that of salsa dancers, and more than half of the members performed them out of time, moving their arms much faster than their feet and tempo of the music.

The arm circles were but one example of a common pattern among outsiders trying to learn salsa that led to the transformation of the genre. That is, newcomers to the style often confused secondary moves for intentional, definitive, primary movements. This was one source for the stylistic discrepancies performed by newcomers to salsa and is, perhaps, a more general obstacle in cross-cultural borrowing. Because of the prestige attributed to ballroom dance and Lin's method, his students remained committed to this style of dancing even as they found it to be incompatible with other salsa dance styles performed at clubs and other social events.

Lin told me that the SFT members also requested particular moves that were consid- 
ered sexy and virtuosic. "They want all this fancy stuff even though they can barely do the basic and have no idea what's going on here [as he gestured to his torso]." In particular, this "fancy stuff" included moves that resembled romantic physical intimacy-running hands through partner's hair, neck wraps, touching of faces/lips, and so forth. Lin did not approve of these moves, which he implied were tacky and "lacking class," but he did his best to oblige, consulting Cordoba for help. Cordoba complied by showing Lin a dozen or so variations on a simple move- the cross-body lead - that incorporated such signifiers of sexuality.

For the SFT Lin created a sequence of moves that culminated in the men leading their partners in a backwards dip, so the women, pelvis to pelvis with their partners, arched backwards and swept their hair along the floor. This move, a potent signifier of dramatized sexual ecstasy, was the most exciting part of the routine for the members. The group considered this the highlight of the routine, and members exhibited a great amount of enthusiasm for the move when Lin first introduced it. In fact, Lin and Irene demonstrated the move at the end of a three-hour rehearsal as a "teaser" for what they would learn in the next practice session. The team was so excited by it, however, that they demanded Lin teach the move to them immediately even though it extended their already long rehearsal by ninety minutes. Learning these types of moves, perceived as explicitly signifying sexuality, allowed SFT members to feel as if they were performing the sensual aspects of the dance even as they continued to struggle with the more difficult and subtle torso movement, the nexus of salsa's presumed sexuality. Essentially, the perceived sexuality of the hip movement was supplanted by other moves of ballroom origin that contained different, theatricalized types of signifiers for sexuality and exoticism.

\section{Stylistic Transformation}

All the SFT members participated in the group in order to improve their salsa dancing and to establish new habits of performance that would garner them acceptance, if not prestige, within the larger salsa dance community. Because they were unable to reconcile the requisite counter-body movement with their movement dialect, however, the style of salsa performed by these newcomers was significantly different than that of insiders and actually acted as a barrier to their acceptance. This type of performance involved exaggerating the ribcage isolation as a demonstration of ability and investment or completely omitting it altogether, resulting in an exaggerated, pendulum-like hip motion. Unrelated to knee and footwork and lacking counter-body movement, this style required more time, space, and energy to produce and caused many dancers to move slightly off time. Because the arm circles were learned independently of the footwork on which they are typically based, they were generally much larger than that of salsa dancers and some performed them out of time, usually moving their arms much faster than the feet and tempo of the music. Furthermore, they performed those moves from the routine that involved theatricalized sexuality and occasionally performed verbatim the routine from the presentational performance.

Generally, this type of salsa performance was perceived by other salsa dancers to be 
"too big," because it literally required more floor space to execute, and "too busy," because too many ballroom-style moves were strung together in complex sequences that were performed somewhat ahead of the music's tempo. Performers who danced in this style were marked as outsiders, and though they were accommodated on the dance floor, they were not openly embraced by members of the salsa community.

A small group of individuals did indeed learn how to perform well enough to be considered at least adequate dancers by insider standards at my field site. Generally, this involved abandoning the fixation on hip action and sexual signifiers and developing other important aspects such as lead/follow, timing, footwork, improvisation, or the incorporation of moves considered more authentic than the ballroom sequences learned by the SFT. Perhaps more importantly, these members also invested time and energy building relationships with salsa dancers off the dance floor, an investment that had positive repercussions for dancing as well. One of the SFT captains, Gabrielle, eventually chose this path after the SFT disbanded. She continued to attend salsa dances, built relationships with many of the dancers by working the door for the Regent salsa nights, hosted salsa parties, and began deejaying salsa house parties. She contributed often to the online salsa discussion list, the most effective local networking mechanism, with announcements about dance events and parties in Urbana-Champaign as well as events in Chicago, including concert dates for popular salsa musicians. Within twelve months she was making headway within the community and eventually established herself as a leader. Her role in the SFT was all but forgotten. In fact, her status as a fixture at local events coupled with her Asian and Jewish physical features caused many subsequent newcomers to mistake her for a Latina. Though she made no explicit effort to mislead or "pass," she was pleased with the mistake.

A small group of SFT members became discouraged, either with their inability to successfully perform the dance or to build relationships with other dancers, and quit completely. For example, the other team captain, Lisa, made initial but unsuccessful attempts to connect with salsa dancers and eventually ceased dancing altogether. Others continued to dance but sought out other genres, such as the swing or tango. In fact, both of the established leaders of the two local Argentine tango associations found their way to the tango through salsa. One of these dancers, Ray, and his partner Juanita (formerly Joann), were first attracted to salsa, but they found the pace too fast and the rhythm somewhat disconcerting. The slower, more dignified tango suited them better. As Ray stated, "I thought salsa was to tango what undergraduate was to graduate school ... that the tango was the grad school of Latin dancing."

The strategies employed to learn salsa during its rise in popularity at my field site produced different styles of performance that were understood by the salsa dancers with whom I worked as markers of different social groups and different sets of social positions. They were received differently according to a wide range of sentiments, from feelings of resentment for the exoticization and accusations of appropriation, to gratitude and honor at the demonstration of investment in increased cross-cultural understanding, to excitement and unbounded enthusiasm for the energy created by the sheer number and variety of dancers on the floor. 


\section{The Performance of Self and Other}

Participation in the SFT challenged all the dancers to attempt moves that did not feel natural-that were not necessarily consistent with their own movement dialect. But it was precisely this challenge that the dancers were looking for. They were hoping to internalize and naturalize the "sensual" aspects of salsa and the "classy" aspects of ballroom and were willing to experience embarrassment in order to do so. Although each individual stated they joined the group to improve their dance style for social dancing, the collective, theatrical, presentation-based goal of the formation team helped the members reconcile their discomfort with these unnatural movements. They repeatedly reminded each other that they needed to take risks and commit to the choreography for the good of the team and the final performance. That these motions were part of a dramatic portrayal, and that they would be performed in costume with masks, helped the SFT members to reconcile their dis-ease with these unnatural movements, which were not legitimated within their own movement dialects. Rather than helping them feel less conspicuous, it legitimated the conspicuousness within the context of collective performance, theater, and costume; and repetition of these movements through numerous time intensive rehearsals and performances helped to eventually normalize them for some dancers.

The component of metaphorical and literal disguise inherent in the theatrical, presentational component of the SFT allowed members to try on new identities, or perhaps explore and push the boundaries of the self. Especially, but not exclusively, among the white, North American members, references to a metaphorical, alternatively racialized self emerged. As one member stated, he joined the SFT to "get ethnic. I'm tired of being white!" Other members believed that deep down they possessed a metaphorical "Latin soul" or "Latin blood" and that their performance of salsa was an attempt to find this imagined, primordial ethnic self. Their performance was the creation of a differently racialized character, a dramatic portrayal of "someone who dances" or, more specifically for these dancers, "a classy, exotic one who dances well." Through this portrayal they attempted to internalize the actions of these "new," more exotic characters, believing, in fact, that this was what it meant to "get ethnic" or to find one's Latin soul.

The donning of literal and metaphorical disguise allowed individuals to perform archetypal narratives of self and other through performance of music and dance. To return to Philip Deloria ( 1998 , IOI), he states, "The authentic ... is a culturally constructed category created in opposition to a perceived state of inauthenticity. The authentic serves as a way to imagine and idealize the real, the traditional, and the organic in opposition to the less satisfying qualities of everyday life ... Because those seeking authenticity have already defined their own state as inauthentic, they easily locate authenticity in the figure of an Other." Deloria's characterization of those seeking authenticity as having already defined their own state as inauthentic resonates with the ways in which these relative newcomers to salsa understood themselves in relation to Latin American dancers.

In her study of white Americans and ethnicity, Mary Waters (1990) concludes that although ethnicity among the white middle class is not perceived to have direct relevance 
or ramifications on their everyday lives (that is, it does not affect where they live or what type of job they have), it is believed to be the source of personality traits. For example, if one is uptight, emotionally demonstrative, speaks with large hand gestures, or is particularly seductive, these are perceived to be qualities attributed to one's ethnicity. She also suggests that claiming some degree of "ethnicity fulfills [a] particularly American need to be "from somewhere" ( 150 ). The "American" need is not only to have a sense of ancestral history and to be part of a larger social collective but also to feel simultaneously unique, a result of the importance of "individuality" in the American psyche. American democracy and the demise of aristocracy, the distinctly American celebration of individualism, and technological advancements significantly altered the ways in which European Americans have connected to their community and family, resulting in a void left by the demise of close familial ties (nuclear and extended) and community associations. Technological advancements such as the automobile, air conditioning, the telephone, and the Internet, as well as changes in residential architecture and civil planning (suburbs), can be understood as contributing to a greater separation of individuals one from another, serving to weaken community ties (Waters I 45-50).

Waters argues that to redress this situation her respondents-white, middle-class Americans-selectively chose to celebrate certain aspects of their ethnicity. She calls this selective, explicit cultivation of certain aspects of ethnic identity "symbolic ethnicity," a concept originally developed by Herbert Gans ( 1979 ). For many whites, their ethnic heritage was simply too vague, complex, convoluted, or unattractive to merit celebration. This type of individual, many of whom are featured in my own ethnographic study, described themselves ambiguously or disparagingly, as "Heinz 57," "mutt," "vanilla," "generic," or lacking in ethnicity at all (see also Lausevic r 998). They were aware that not only is it good to have a singular sense of ethnic identity but that certain ethnic identities are "better," or more highly valued, than others. When asked what ethnic identity they would prefer if they could choose from any, Waters's respondents overwhelmingly said they would choose to be part of a "living ethnicity," one that is not diluted or antiquated (like their own). In the case of third- and fourth-generation European immigrants, their ethnicity is perceived to be something other than "living"-an artificial perpetuation of outdated, inauthentic practices. Her respondents cited other groups or romanticized places-Native Americans, Gypsies, or a mythical rural homeland or ethnic ghettos-that are perceived to have stronger family ties and rich, "thick" cultures that were not "uptight" (Waters I990, I 52 ). These responses echo those of my own case study, where Latin American culture, understood generally as a monolithic entity, was perceived as a highly desirable ethnicity. Latinos were understood to have strong familial and community ties, to be physically and sexually relaxed and open without impropriety, and to possess a "living" culture of which salsa music and dance was an integral part. Though it may have been impossible to "become" a Latino, my informants were drawn to salsa and tango (and other Latin American expressive forms) as a means of acquiring the positive qualities they associated with Latin Americans. Waters suggests that for white, middle-class Americans, ethnicity is generally understood as a choice that provides some type of social pleasure-what she coins a "costless community." Whites erroneously superimpose this conception of

\section{(1)}

\section{Da}


ethnicity to others (especially racial minorities), leading to racial misunderstandings and tensions such as those I experienced in my field site.

We may conclude two things from Waters's study: first, that certain ethnic groups (or the stereotypes of certain ethnic groups) are valued relatively within larger society, and individuals measure the relative social value of their ethnic affiliation (if any) to that of other possibilities; second, that individuals who are dissatisfied with their "ethnic options" and the cultural and personality traits attributed to them (or if they feel they can make no legitimate claim to one ethnicity) turn to the cultural practices, such as music and dance, of other groups as a means of satisfying inadequacies in their own lives. My fieldwork experiences echo Waters's research. When confronted with difference on the dance floor, the non-Latin dancers with whom I worked began to wrestle with ambiguous feelings about their own sensuality and sexual prowess relative to Latin American salsa dancers. They attributed this difference to ethnic heritage, considered their own ethnicity of relatively little value, and turned to the cultural practices of Latin Americans in hopes of finding some satisfaction. Even the few international members of the group expressed that Latin American culture was relatively more prestigious (more "cool") within local social networks than their own cultural heritage from Asia, the Middle East, or the Mediterranean.

These dancers wanted to "get ethnic," to obtain the beneficial aspects they perceived to be inherent in Latin American ethnicity through the performance of salsa. The performance of Latin dances helped non-Latinos remake themselves anew through the internalization of favorable aspects of Latin American ethnicity. However, this internalization - the embodiment of new physical habits understood to be more liberated, relaxed, and sexual-was not discussed as something new at all but rather as an excavation of something that had pre-existed in the self. What was described was not an internalization of a foreign other but rather an externalization of something within, an affirmation of the existence of an exotic self believed to be buried deep in the psyche. Beth, a dancer in the SFT who identified as a European American (of mixed Irish and Polish descent), said she danced salsa because it "has the spice of 'my' Latinness" [her quotation marks]. Her choice to frame the word "my" in quotes characterizes the understanding that this is not a reference to any type of literal ancestral lineage but instead a type of metaphorical conceptualization of a "spicier," more exotic, component of the self for which she has no other language. Although it was often couched in these terms, SFT members did not choose to dance Latin dances because they were ultimately desirous of a Latin American ethnicity. ${ }^{4}$ They desired to construct for themselves an alternative sense of self that they perceived to be more "vibrant" or "alive," more physically integrated, and more sexually attractive. But there existed no language and few conceptual categories for such a construction of their own, largely unmarked identity. ${ }^{5}$ Latin American ethnicity, or preconceived notions of it, served as the cognitive conduit through which this type of identity could be cultivated.

For members of the SFT, dance became a type of theatrical performance in which characters could be created and hopefully internalized. I am moving now beyond the literal costume to the metaphorical one that exists in the imagination and the creative 
play of being simultaneously self and other that informed their particular style of salsa dance. The structuring capabilities of habitus and movement dialect precluded the habituation of movements that were incompatible with their class- and race-based aesthetic disposition and affirmed those that resonated most strongly with the aesthetic ideals of their particular cosmopolitan worldview.

The theatrical and presentational aspects of the SFT's performance were helpful in allowing members to bridge the ideological identity gap between the individual they perceived themselves to be and the one they hoped they would become through performance. The masking device of presentational, theatrical performance helped dancers remain in a newly imagined cognitive space, where established habits were denied and new identities could emerge. While performing salsa, dancers tried their hand at using different body muscles, facial expressions, hip movements, and arm sweeps-movements they perceived to be laden with an unfamiliar physical liberation and sexuality and hoping that some residue of this sexuality would remain when the music had stopped.

To conclude, I have suggested that a new kind of salsa dance has emerged among nonLatino, upper-middle-class, cosmopolitan audiences in the North American Midwest. Rather than considering the style an incorrect or "broken" interpretation of what may be perceived as something more "authentic," my treatment of it here has implied that, while perhaps based in some misconceptions, it has become an independent and distinct phenomenon and part of a long-standing collection of Americanized Latin American genres.

I have also suggested that this stylistic transformation is driven by a number of factors that are themselves rooted in notions of transformation at a personal and cultural level. In fact, I would extend the argument to suggest that artistic innovations such as this are often responses to particular cultural problems that require personal and cultural transformation (see also Ackerman 1962 and Peña 1985 ). As changing perceptions of race and ethnicity in the United States cause increased anxiety among upper-middle-class Americans, they turn to performance as one potent means for struggling with their relationship to a legacy of white dominance, the contemporary discourse of multiculturalism, and the increasingly interconnected and integrated state of American society today. Regardless of how we, as scholars and artists, feel about this response-and it is common parlance to dismiss this type of performance as unartistic, inauthentic, and socially problematic-its sheer ubiquity demands that we move beyond our own discomfort with it in order to examine its causes and effects in American popular culture. Only by doing so can we, as scholars, artists, and citizens, hope to usher in a new era of frank, honest, and equitable discussions about the nature of race and performance in contemporary America.

\section{Acknowledgements}

This piece has benefited from the thoughtful comments of many readers. An earlier version of this article was presented at Music and Identity, a conference on cross-cultural borrowing at Brown University. I am especially grateful to Marc Perlman for his unique vision in organizing the conference and his thoughtful comments regarding the ideas presented here. I also extend my gratitude for the contributions of the conference par- 
ticipants, especially Mirjana Lausevic, Ian Condry, and David Samuels. Special thanks also to Marisol Berios-Miranda, Dominique Cyrille, Howard Spring, June Vail, and Mary Hunter for providing helpful comments on an earlier draft; Christopher Scales for reading and commenting on several earlier drafts; and my doctoral dissertation committee, Bruno Nettl, Thomas Turino, Donna Buchanan, and Cynthia Oliver, who were instrumental in shaping my ideas on this topic. Research for this project was partially funded by the Society for Ethnomusicology Nadia and Nicholas Nahumck Award for Dance Research.

\section{Notes}

I. To protect the privacy of my informants, I employ pseudonyms throughout this text with the exception of the professional dance coaches cited, David Lin and Enio Cordoba.

2. Thomas Turino's concept of cosmopolitanism is helpful for understanding how shared, classbased values obscured the otherwise international and heterogeneous constitution of the group of dancers discussed in this work. Most generally, cosmopolitans hail from the economic or educated elite of their society and affirm a number of translocal formations cultivated in and distributed from urban centers, such as the "political validity of the nation-state, the use of money, and industrial production" (2000, I0). In terms of the arts, I would add to this list a preference for complexity, virtuosity, and restraint within goal-oriented forms and the valuation of aesthetic distance, control, and discipline couched in the discourse of sophistication. With very few exceptions, all the dancers I worked with were cosmopolitan in this sense of the term, or were participating in cosmopolitan practices with the goal of upwards mobility, and both ballroom and salsa dance formed a central part of this project.

One of the most striking aspects of ballroom dance is its symbolic significance internationally-its efficacy as a locally specific phenomenon and nexus for an international, intercontinental community. As a pre-eminent expressive form during late colonization and the High Modern period, ballroom dance is embedded in cosmopolitan formations and performed in urban centers around the world, from Chicago to Shanghai, Toronto to Tokyo. Ballroom arises among particular social groups in dispersed locales and is a "specific type of cultural formation and constitution of habitus that is translocal in purview" (Turino 2000, 7). Ballroom dance is not specific to a single or even a few neighboring locales; instead it is situated in many sites that are connected not by geographical proximity, but by other forms of contact such as print, visual, and audio media, Internet Websites and discussion lists, and international competitions (annual, short-term events that rotate location). Most important, and this is especially the case for ballroom dancers, "cosmopolitan groups are connected across space by a similar constitution of habitus itself, which creates the foundation for social communication, alliances, and competition" (Turino 2000, 8). While this article is, in essence, a foray into the shared aspects of habitus for a local group of Midwestern American dancers, the cosmopolitan nature of ballroom dancing results in commonalities that cross regional and nation-state boundaries as well.

One quality of the social dance scene of this case study that distinguishes it from other works on salsa (and other popular dance music studies) is the particular rural yet cosmopolitan nature of Urbana-Champaign, a college town in central Illinois. Generally, qualities ascribed to the entertainment industry of urban centers are presumed to hold true for localized manifestations within less populated areas. My work suggests that large-scale generalizations of the entertainment industry fail to capture the economic realities for all of those who live outside of urban centers but remain connected to them via cosmopolitan pathways of transmission. 
Out of the particular juxtaposition of rural, agrarian pragmatism and university intellectualism that characterizes Urbana-Champaign, Illinois, emerged a unique ethos combining various aspects of cosmopolitanism and parochialism. Specifically, a smaller, rural community such as this, which nevertheless hosts residents from around the world-many of whom are members of the middle and upper classes from their respective regions and adherents to some degree of cosmopolitan values-cannot sustain independent, compartmentalized entertainment venues for various regional styles. There can be no Chinatown, Little Italy, or Little Havana in a region such as this. In Urbana-Champaign at the time of my fieldwork, there were few live music venues, and as such they were shared to some degree among constituencies, all of which eventually developed a sense of ownership for the space. This intersection of audiences and social spaces created opportunities for specific types of cross-cultural experiences that are not found in the more clearly demarcated ethnic neighborhoods of many metropolitan areas.

3. This is an important point. When asked by outsiders to explain the "hip thing," they exhibited surprise, not really conceptualizing of their movement as being generated from the hips. I have found Polanyi and Prosch's (r 975) concept of focal awareness useful for understanding the various levels of attention employed during dancing and prefer this to the more common conceptual framework for awareness: the dichotomous Freudian distinction between conscious and subconscious.

4. This statement is meant in no way to suggest that "I know better" than my informants in some type of modernist rhetorical gesture. Rather, it is a distillation of my discussions with informants, who initially couched their desire in terms of ethnicity but gradually moved into a discussion of physicality utilizing the racialized language of ethnicity.

5. Although there are many privileges to being in the unmarked category, this is one of the problematic outcomes.

\section{Works Cited}

Ackerman, James. 1962. “A Theory of Style." Journal of Aesthetics and Art Criticism 20 (3): 22737.

Aparicio, Frances. 1998. Listening to Salsa: Gender, Latin Popular Music, and Puerto Rican Cultures. Edited by E. E. George Lipsitz. Hanover, CT: Wesleyan University Press.

Berrios-Miranda, Marisol. 2003. "Bailando Salsa en la Sala, Como Aprendimos a Bailar y a Vivir." Paper presented to the Annual Meeting for the Society of Ethnomusicology, Miami, Florida, October 4.

Bosse, Joanna. 2004. "Exotica, Ethnicity, and Embodiment: An Ethnography of Latin Dance in US Popular Culture." PhD diss., University of Illinois, Urbana.

Bourdieu, Pierre. 1977. Outline of a Theory of Practice. Cambridge: Cambridge University Press. Deloria, Philip. 1998. Playing Indian. New Haven, CT: Yale University Press.

Duany, Jorge. 1984. "Popular Music in Puerto Rico: Toward an Anthropology of Salsa." Latin American Music Review 5 (2): 186-2 I6.

Gans, Herbert et al. 1979. On the Making of Americans: Essays in Honor of David Riesman. Philadelphia: University of Pennsylvania Press.

Hosokawa, Shuhei. r 997. “'Salsa no tiene frontera': Orquesta de la Luz or the Globalization and Japanization of Afro-Caribbean Music." Revista Transcultural de Música 3: I-2 I. Available at http://www.sibetrans.com/trans/trans 3 /indice 3. htm.

Keil, Charles. 1987. "Participatory Discrepancies and the Power of Music." Cultural Anthropology $2(3): 275-83$.

- I 995. "The Theory of Participatory Discrepancies: A Progress Report." Etbnomusicology 39 (I): I-20. 
Lausevic, Mirjana. I 998. "A Different Village: International Folk Dance and Balkan Music and Dance in the United States." PhD diss., Wesleyan University.

Loza, Steven. I 993. Barrio Rbythm: Mexican American Music in Los Angeles. Urbana: University of Illinois Press.

Manuel, Peter. 1994. "Puerto Rican Music and Cultural Identity: Creative Appropriation of Cuban Sources from Danza to Salsa." Ethnomusicology 38 (2): 249-80.

Peña, Manuel. I 985 . "From Ranchero to Jaitón: Ethnicity and Class in Texas-Mexican Music." Etbnomusicology 29 (I): 29-55.

Penny, Patricia A. 1997. "Contemporary Competitive Ballroom Dancing: An Ethnography." PhD diss., University of Surrey.

Polanyi, Michael, and Harry Prosch. 1975. Meaning. Chicago: University of Chicago Press.

Turino, Thomas. 200o. Nationalists, Cosmopolitans, and Popular Music in Zimbabwe. Chicago: University of Chicago Press.

Waters, Mary C. 1990. Ethnic Options: Choosing Identities in America. Berkeley: University of California Press.

Waxer, Lise. 2002 a. The City of Musical Memory: Salsa, Record Grooves, and Popular Culture in Cali, Colombia. Middletown, CT: Wesleyan University Press.

,ed. 2002 b. Situating Salsa: Global Markets and Locating Meanings in Latin Popular Music. New York: Routledge. 